\title{
Utilizing an Innovative Engineering Skills Curriculum and Technology to Ex- pand Classroom Learning in Low-Resource Settings
}

\section{Mr. Dhinesh Balaji Radhakrishnan, Purdue University}

Dhinesh Radhakrishnan is a doctoralstudent in the School of Engineering Education at Purdue University. His research includes utilization of technology in education, and socially constructed education in lowresource settings. His current work is on developing engineering skills curriculum for out-of-school youth in Africa utilizing digital learning materials. He is the Global Student Forum Chair for 2016 in SPEED. $\mathrm{He}$ is also the CoDirector of Footsteps. He has been associated with SPEED for the past 6 years and served in various positions. He holds a Bachelor in Electrical Engineering and Masters in Energy Systems (Specialization in Renewable Energy).

\section{Prof. Jennifer DeBoer, Purdue University, West Lafayette}

Jennifer DeBoer is currently Assistant Professor of Engineering Education at Purdue University. Her research focuses on international education systems, individual and social development, technology use and STEM learning, and educational environments for diverse learners. 


\title{
Utilizing an Innovative Engineering Skills Curriculum and Low-Cost Digital Technology to Expand Classroom Learning in Low-resource settings
}

\begin{abstract}
With this work-in-progress paper, we report on the design of an innovative curriculum focusing on engineering skills for low-resource pre-college students. Engineering knowledge and skills are in high demand for local and global knowledge economies and provide individuals access to social and economic mobility. However, basic engineering education is inaccessible to many students in low-income and low-resource areas. Educational technology may be one component of a solution that addresses access and equity.

The curriculum focuses on science and engineering problem solving within real world contexts. We adopt the Integrated Course Design for Outcome-Based Education approach ${ }^{1}$ for this design. This curriculum comprises four unique components: (1) using technology for access to learning modules, (2) taking advantage of the residential environment and delivering content in a flipped structure, (3) utilizing service learning by building on community needs for engineering problems, and (4) iteratively developing the curriculum in close concert with teachers and students. This course is currently designed for out-of-school youth at a residential children's transition center located in western Kenya in a peri-urban agricultural area outside a major urban center. We apply backward design ${ }^{2}$ in developing the curricular priorities and content to be delivered based on the learning objectives defined along with the center director and students. The course aims to prepare students for adaptable problem-solving, design, and evidence-based decision making.

This curriculum is a unique form of experiential education based on a synergistic model in which academic objectives are integrated with community development and collaborative learning. We believe that the learning from this curriculum will equip them with a set of transferrable skills, that will help the students build relationships with their community and find employment opportunities. Further, their emerging ability to create their own solutions could be scaffolded into learning entrepreneurship and other opportunities in future courses. The course is built on findings from previous work showing promise for increased learning outcomes from flipped classroom platforms and student-driven curricula. The paper provides an overview and describes the development of the first and fourth component of the curriculum, i.e. the role of technology and the content for the course planned until the publication of this paper, and it serves primarily to document the design and initial development phases of the ongoing project.
\end{abstract}

\section{Introduction}

One of the most pressing topics in educational development has been the need for educational access and equity for diverse students and the potential role of technology to achieve this inclusion. To achieve this objective, the educational context needs consideration, in particular with respect to available resources and existing social, political, and cultural structures. To design an enriching educational experience, it is important to understand the purpose of education for the desired group of students. Dewey, in his book on experience and education, proposes that the purpose of education is to build the capacity of youth to take on future 
responsibilities and be successful in life, through the acquisition of organized bodies of information and prepared forms of skill that are effectively transferred from the instructional material $^{3}$. Some amount of contextualization is necessary to appropriately design any educational structure for a given setting. A growing body of research suggests that overall student achievement is likely to increase when students are able to learn at their own pace, with a variety of teaching styles and formats available to them, and with a curriculum that is relevant and tailored to their environment. This paper provides a description of the development of one such curriculum.

\section{Characteristics of the setting}

The curriculum currently under development is a 20 -week course for out-of-school youth at a residential center called Tumaini Innovation Center in the city of Eldoret, Kenya on engineering skills and hands-on application of those skills taught with the support of digital materials to meet local community needs. Over the past six years, the center has worked with thousands of out-ofschool youth to prepare and support their reintegration into the traditional Kenyan education system $^{4}$. To achieve this objective, participating youth themselves explained that the center needed a more permanent space to deliver a more intensive and formalized education structure. The residential center was established in 2014, housing and educating 11 children and later recruiting 3 more children in 2016. The center has since operated as a school that provides the basic content required in the formal education system. Some of the basic subjects covered are English, KiSwahili, Science, Mathematics, Social Science, and Religion. According to a global health development survey conducted by the World Bank in Eldoret, the location of the center currently could be categorized as a lower middle income context ${ }^{5}$.

\section{Characteristics of learners}

The assumption on the part of formal teachers in the region is that often these students are viewed as incapable or underperforming in the context of learning inside a classroom and lacking the skills necessary to succeed ${ }^{6}$. The reality is in stark contrast to these assumptions. Masita and coauthors ${ }^{7}$ present their observations of African youth's perspectives and attitude towards education, stating, "Youth were found to have an appreciation for education especially as a means to gainful employment, stature and respectability. Education is also seen as a means to gain social skills such as language, poise and even how to carry one's self' (p. 522). One of the main objective of Tumaini Innovation Center's is to develop the and motivation to become socially recognized and self-confident humans ${ }^{8}$.

The eleven students range in age from 12-17 years. The students are also diverse with respect to their prior knowledge. Two of them have no prior formal education while others have had varied levels of basic primary level education. Individual and communal responsibilities are shared in terms of students' day to day tasks in taking care of the center and being accountable for their actions. For example, the students themselves created rules governing clean conduct that they are to abide by while living at the center. This provided a feeling of ownership the students take over the center and over their own education. 


\section{Technology in action}

Technology as a tool to aid ${ }^{9}$ in access to education is an important aspect of this curriculum. The technological tool being adopted in this curriculum is a tablet with a pre-installed learning platform. The learning platform is designed and developed by a leading mechatronics company Quanser in Canada. The platform requires authoring the content using XML programming language via computer editor software. The tablet performs the role of a modernized and interactive textbook. However, the importance of face-to-face interaction and facilitation by the teachers is necessary to ensure construction of meaningful learning experiences ${ }^{10}$.

\section{Method}

The development of an effective curriculum is a multi-step, ongoing, and iterative process ${ }^{11}$. There are numerous opportunities to evaluate and improve the educational process and core content as part of thoughtful curriculum development. An important way to ensure this improvement is through continuous documentation of the development process. The method section below documents the process that we carried out in the design and development of this curriculum. Table 1 provides an outline of the activities that have occurred in the initiation and planning phases from the start of the project until now.

Table 1 Outline of development activities

\begin{tabular}{|c|c|}
\hline Timeline & Actions Involved \\
\hline May 2015 & $\begin{array}{l}\text { Initiation of project with approval for collaboration between the researchers and } \\
\text { the residential education center in Western Kenya }\end{array}$ \\
\hline June 2015 & $\begin{array}{l}\text { Initial visit to the center for two days by one of the researchers for scoping the } \\
\text { project and initial gathering of needs }\end{array}$ \\
\hline \multirow[t]{2}{*}{ July 2015} & Identification of potential collaborator for technology service provider. \\
\hline & Dialogue building and agreement on collaboration with company X \\
\hline \multirow[t]{2}{*}{$\begin{array}{l}\text { August } \\
2015\end{array}$} & $\begin{array}{l}\text { Planning meeting between center director and researchers } \\
\text { - Understanding timeline } \\
\text { - Understanding resources } \\
\text { - Planning for regular interaction and feedback (Initially planned to have } \\
\text { weekly meeting with Center Director, but due to availability constraints it } \\
\text { later became bimonthly meetings) }\end{array}$ \\
\hline & Initial work on framing of learning objectives \\
\hline \multirow{3}{*}{$\begin{array}{l}\text { September } \\
2015\end{array}$} & Design of curriculum - Finalizing curriculum objectives \\
\hline & Curriculum timeline development \\
\hline & Bimonthly update and feedback meeting with Director of the center (via Skype) \\
\hline \multirow{4}{*}{$\begin{array}{l}\text { October } \\
2015\end{array}$} & Initiating content development \\
\hline & Development of modules (lessons) \\
\hline & Storyboarding modules to be coded into the learning platform \\
\hline & Bimonthly update and feedback meeting with Director of the center \\
\hline
\end{tabular}




\begin{tabular}{|l|l|}
\hline $\begin{array}{l}\text { November } \\
2015\end{array}$ & $\begin{array}{l}\text { Initial discussion with company X for visit to researcher's location and detailed } \\
\text { meeting on further expanding the platform }\end{array}$ \\
\hline $\begin{array}{l}\text { Officials from company X visit researchers and augment of learning applications } \\
\text { (including interactive simulations mentioned below) }\end{array}$ \\
\hline $\begin{array}{l}\text { December } \\
2015\end{array}$ & Development of modules as applications in the learning platform \\
\hline $\begin{array}{l}\text { January } \\
2016\end{array}$ & $\begin{array}{l}\text { Update and feedback meeting with Director at the center along with the students } \\
\text { the section Beta-test }\end{array}$ \\
\hline
\end{tabular}

Phase 1 - Curriculum Development (May - December 2015)

The objectives of the curriculum were developed in consultation with the students, teachers, and the director of the center based on the immediate development needs of their local community. The semester 1 course will be implemented from May to December of 2016. It is designed to address the lack of a reliable energy source needed to access water for the center's farm. The students will engage with engineering knowledge, skills, and attitudes as they collaborate on designing and constructing a solar powered water pump.

For the development of this curriculum, the backward design model ${ }^{2}$ was adopted. To create curricular priorities, the backward design model first seeks to answer the question -- what do we want the students to know? After this, Streveler et $\mathrm{al}^{1}$ propose to answer two additional questions: what do we want the students to do?, and whom do we want the students to be? (detailed in table 2) The answers to these three questions are the three apprenticeships that Sullivan and Colby ${ }^{12}$ describe in the Carnegie Preparation for the Professions Program as the apprenticeship of the head (intellectual development), the hand (skill development), and the heart (development of habits, mind, values and attitudes).

Table 2 Answers to Backward Design questions to develop curricular priorities

\begin{tabular}{|c|c|c|}
\hline $\begin{array}{c}\text { What do we want } \\
\text { students to know? } \\
\text { (Intellectual } \\
\text { development) }\end{array}$ & $\begin{array}{c}\text { What do we want the students to do? } \\
\text { (Skills development) }\end{array}$ & $\begin{array}{c}\text { Whom do we want } \\
\text { the students to be? } \\
\text { (Habits } \\
\text { Development) }\end{array}$ \\
\hline $\begin{array}{l}\text { Fundamentals of science } \\
\text { and engineering related } \\
\text { to semester } 1 \text { course: } \\
\text { Water cycle, access to } \\
\text { water, liquid flow } \\
\text { properties (pressure, } \\
\text { volume, temperature) } \\
\text { light properties } \\
\text { (radiation, reflection, } \\
\text { refraction, insolation), } \\
\text { electricity basics, } \\
\text { (current, voltage. }\end{array}$ & $\begin{array}{l}\text { - Display understanding of science and } \\
\text { engineering fundamentals } \\
\text { Problem-solving (systematic problem-solving } \\
\text { methodology, i.e., problem scoping, evaluation, } \\
\text { statement development) } \\
\text { - Identify the problem: Access to water at the } \\
\text { center in problem scoping session } \\
\text { - Using the problem statement develop the } \\
\text { solution process to translate written } \\
\text { statement into solution model } \\
\text { Design (Design process methodology) }\end{array}$ & $\begin{array}{l}\text { Self-confident } \\
\text { humans } \\
\text { Rational \& } \\
\text { Creative thinkers } \\
\text { Thoughtful team } \\
\text { workers }\end{array}$ \\
\hline
\end{tabular}




\begin{tabular}{|c|c|}
\hline $\begin{array}{l}\text { resistance), solar } \\
\text { geometry (daylight } \\
\text { time), solar panel } \\
\text { characteristics } \\
\text { (Photovoltaic, panel } \\
\text { configuration, panel } \\
\text { arrangement) }\end{array}$ & $\begin{array}{l}\text { - Apply design process to generate ideas, } \\
\text { model, analyze predict and build the } \\
\text { solution product, } \\
\text { Professional development (Language, self- } \\
\text { confidence, team work) } \\
\text { - Perform the tasks collaboratively and } \\
\text { communicate effectively the ideas and } \\
\text { solutions }\end{array}$ \\
\hline
\end{tabular}

Based on the answers to these questions, curricular priorities for semester 1 were framed. Students' prior knowledge, motivations, attitudes, and beliefs were identified before developing the curricular priorities detailed in figure 1. An initial visit to the center by one of the researchers in early June 2015 helped in acquiring the initial information necessary through a short interview with two students and a teacher. Information obtained from the visit consisted of student selfreports of their earlier experiences in formal education, their comfort in numeracy and literacy, their personal goals, and their interests in active classroom environments. From the start of the project there have been monthly interactions with the director of the center. These meetings were structured to provide developmental updates on the project, gain feedback, and also gather more information from the director pertaining to the students, teachers, and context of the center. It came to our attention from these exchanges that close to half of the students performed well in science and the remaining students performed well in mathematics. More information about students' interests in performing hands-on activities was referred to consistently during our planned interactions.

Education in engineering should ideally provide and strengthen understanding of such topics related to technical expertise, social awareness, and bias towards innovation to be successful ${ }^{13}$. To begin strengthening these areas, our curriculum focuses on key pre-requisites such as basic engineering experiences or skills in mastering meaningful engineering problems. The concept map shown in figure 2 has a strong primary focus on building up students' exposure to engineering and understanding the meaning of engineering for oneself. The course curriculum is created and tailored to the context of the community in western Kenya by adopting the approach of experiential learning, making engineering examples relevant to this community, and incorporating both Project Based Learning (PBL) and Service Based Learning (SBL). 


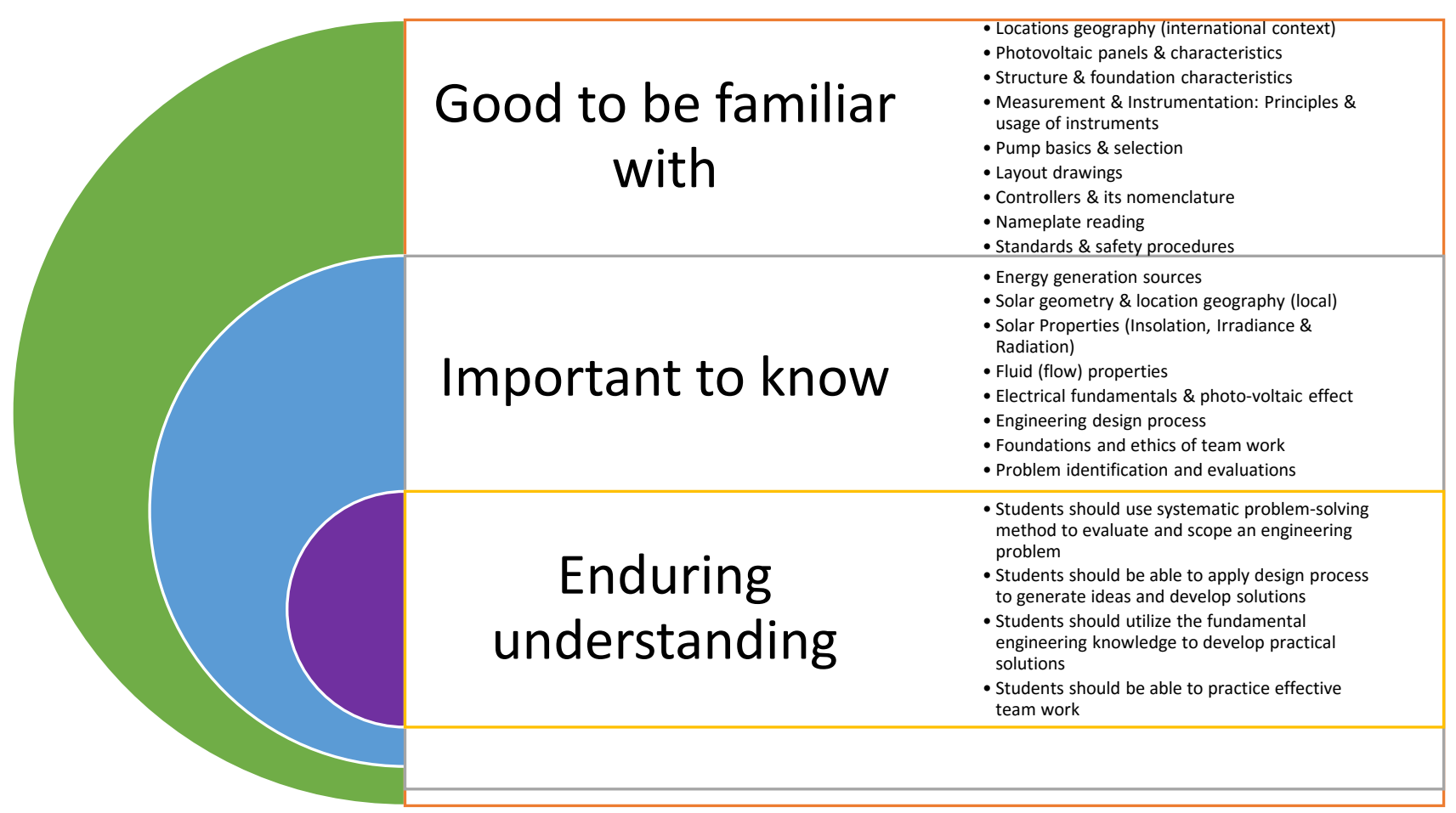

Figure 1 Curricular priorities

Academic objectives are focused on learning the concepts associated with the basic science and engineering fundamentals necessary for a locally-relevant engineering solution to be developed. In this case, semester 1 focuses on the solution of building a solar powered water pump, which requires learning the concepts of basic electricity, basic fluid dynamics, pumps and their operation, and fundamentals in solar geometry. Conceptual learning is combined with hands-on activities via experiential learning. The conceptual learning and hands-on activities will continue to go in parallel through the course, which will largely focus on the process of design and engineering problem-solving. The development of skills requires practice, and the students must have multiple exposures to using new information in order for learning to last ${ }^{14}$. Therefore, acquiring skills is embodied within the problem-solving activities and the design process, as students tackle the challenge of developing a solution to a problem in their own community. The students will adopt and practice all of the steps of the engineering design process: problem scoping, need finding, concept generation, concept reduction, concept selection (and associated evaluation and analysis), solution sketching and detailing, solution evaluation, solution communication, solution implementation, and solution and process reflection. The skills, knowledge, and attitudes that students gain through these experiences will not only foster creativity and support students' personal and social growth, but they will be broadly transferable across a range of labor market opportunities.

The weekly meetings with the Director of residential center helped us to understand that their goal in utilizing the learning platform was as a tool to access educational content. The Director and students at the center were interested in content that would provide the technical knowledge needed for the students to build solutions for their community problems. 


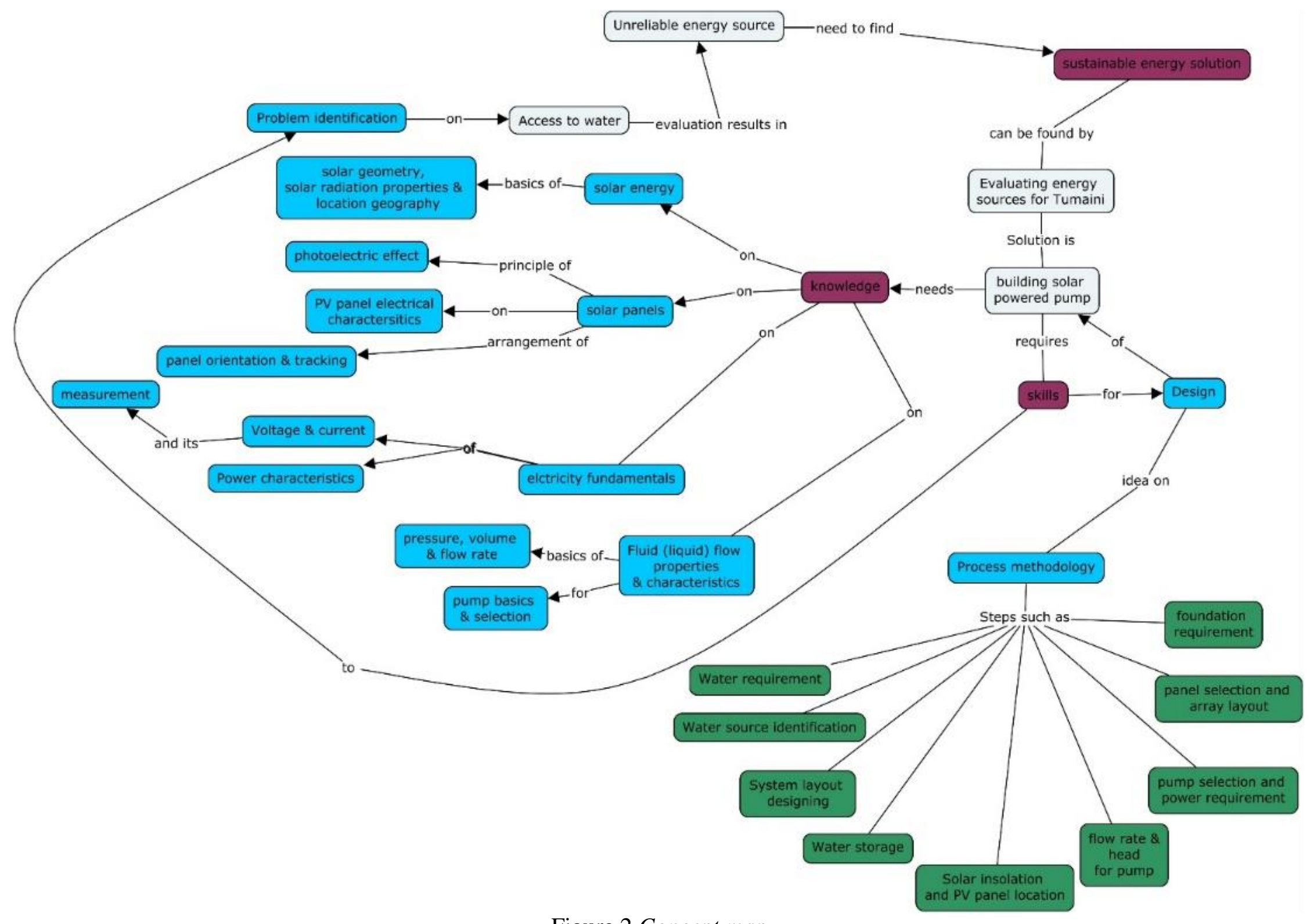

Figure 2 Concept map 
These interactions helped us in understanding the requirements as desired by the students and the director and as well continue to develop the project in line with the expectation while continue to explore new opportunities and developments. Exploring new opportunities helped researchers to view the learning platform as an experimental tool that could provide various formats of learning materials that could assist each student into active learning.

The learning platform developed by Quanser was initially designed as a tool for converting textbook content or self-authored content into a basic interactive application accessible on mobile devices. The platform was designed and developed for use by students at the university level around the world. The platform did not require many modifications to adapt to a traditional university engineering classroom context, as it was built to address the common format of transferring learning content. However, during the month of November (Table 1), researchers and industry officials from Quanser discussed pushing the platform beyond their preconceived expectations. During their conversation, the new approach of using the tablet and the platform as a tool to actually perform engineering tasks and activities was conceived. As part of an ongoing effort, the platform was used to begin coding simulations as a way to represent engineering concepts. The first simulation that was developed is shown in Figure 3. It demonstrates the concept of access to water. The simulation comprises a solar panel that powers two water pumps of different capacities. The first water pump is used to transport water from a natural water reservoir to an underground tank. The second water pump is used to transport water from the underground tank to the house tap. The simulation contains interactive command buttons that engage the student in performing actions and then witnessing the change of colors through the lines. (The single line represents electrical wire, and the parallel lines represent pipes.) The kind of course content was developed to present information in multiple modes, an effective approach utilized throughout the platform ${ }^{15}$. Some of the features utilized to provide variety in the format of the content were images, GIFs, animations, videos, interactive simulations, and multiplechoice questions to check understanding.

\section{Module - Simulation}

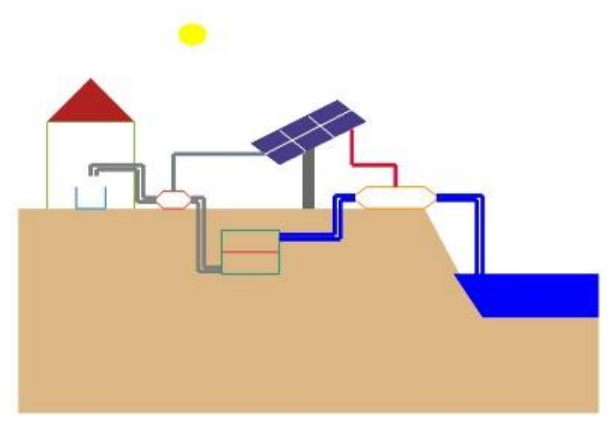

Turn Off Pump 1

Turn On Pump 2

Figure 3 Interactive Simulation on Accessing Water through Solar Power 


\section{Phase 2 - Beta-test}

Identifying the curriculum objectives followed by the development of curricular priorities and a course concept map serves as a valuable start to the development of course content. Ideally, the project was designed to conduct a beta-test after the completion of the first phase of the project, the design of the complete curriculum structure and implementation of all lessons into the platform. With the constraints on time to be able to complete the entire first phase, the development of the content for the complete course was not possible. Therefore, we conducted the beta-test with the material that was ready to be tested. While the terminology "beta-test" implies trial of the product in the final stages of development, we continue to use the term here well before the final development as it served as an important stage in the project development process.

A field visit was made to the center in order to conduct the beta-test. The aim of the beta-test was to evaluate three key components for the success of the project: students' interaction with and comfort in using the tablet, students' ways of utilizing and challenges in using the platform, and students' feedback on the course content and its structure.

The one-week field visit was structured for the following purposes:

1. Introduce and familiarize the students with the use of the tablet and the platform

2. Conduct class sessions of the modules developed

3. Perform hands-on activities that could assist in learning the content

4. Facilitate the development of a definition of engineering and an understanding of the identity of an engineer

5. Understand and evaluate the comfort of teachers in handling a course of such a new format

6. Identify potential collaborative partners from an engineering university located in the same town as the center

On day 1, the beta-test week began with delivering the tablets and introducing the students and teachers to the tablet and the platform. Students were taught a number of ways to personalize their tablets and were prompted in an exercise to set rules for protecting their tablets. The students then participated in an activity thinking about the meaning of engineering to them. The students drew pictures of their perception of "what is engineering?" The teachers were continuously involved in the sessions serving two different functions: 1 . to absorb the structure, develop their own meaning with the curriculum, and get an idea of the pedagogical strategies used by researchers, and 2. to be translators when required.

On day 2, the students were briefed about the curriculum, its overall structure, and its objectives. The teachers were briefed earlier about the schedule for the day and provided feedback on the content and flow of sessions.

On day 3, the students were introduced to an actual course module on water. The module consisted of learning about water, water distribution on earth, and the water cycle. To understand the water cycle, the students performed an activity observing evaporation and condensation in the center's kitchen. Following the activity, the students were prompted to use measurements as 
a tool in applying their knowledge of evaporation. The students measured the depth of a fish pond located at the center and were probed with questions including the following: will the depth of the fish pond always stay the same? The students were able to apply their knowledge of evaporation to relate and answer these questions. The teachers and researchers took part in a debriefing session during the lunch time. The debriefing sessions were used to obtain feedback and also understand the comfort of the teachers in handling the new curriculum format and style in their own practice.

On day 4, the students were introduced to an engineering activity on construction. To address the need for a flagpole in the center, the students scoped the idea, planned the design, performed measurements, identified materials, acquired them, and constructed a holder for a flagpole. This activity was designed to introduce students to various tasks that engineers perform and the process they follow. The students were also later taught about problem scoping and were provided a homework challenge of identifying an engineering problem within the center community that they could address. Later in the day, the teachers themselves facilitated a class session using the tablets. On day 4, pilot data collection began in the form of interviews with the students individually and with the teachers as a group. The interview protocol was previously designed and pilot tested using an external volunteer.

On day 5, potential collaborative partners from the nearby engineering university (both administration and students) were invited. The engineering students were paired with the students at the center to carry forward the problem scoping homework to the subsequent stages of need finding and concept generation. The student pairs developed and designed solutions to address the problem scoped by each individual student.

\section{Discussion}

From the general feedback obtained from the Center students (via initial interviews) and the teachers (via debriefing sessions), the content and delivery of the test modules proved to be effective, and so the content of the test modules will be used to complete the remaining modules. The teachers and students also identified areas for iterative improvement in the content and structure of the curriculum and platform. From the beta-test it was also learned that the students are able to understand concepts that are taught ahead of their commonly accepted educational capacity measured through age and prior knowledge, if appropriate instructional methods were used. Within the constraints of time, the researchers conducted interviews with four student participants at the end of beta-test. The interview was conducted for the students to share their experiences with the tablet, with the platform and with the new model of curriculum and learning. The transcribed student's responses were read multiple times by the primary author to roughly discern common themes. The table below represents the student responses and themes that emerged. 
Table 3 Themes developed from student responses about their experiences during beta-test

\begin{tabular}{|c|c|}
\hline Interview Quotes & Theme \\
\hline $\begin{array}{l}\text { The internet is a bit raw. Okay. Using the internet is trouble. } \\
\text { So I have been very interested to Google maps, but what's the } \\
\text { opposite is that the gadget the Google does not open. } \\
\text { They (researchers) already put the answers. And, it's easy } \\
\text { because you already know that. And you saw the answers. So, they } \\
\text { think you'll be yourselves to listen at the class and pay attention. So, } \\
\text { when you listen, you'll come up with the answer. But, others know the } \\
\text { answer by looking at it. They shout it. But, they actually not know the } \\
\text { answer. It is not good. }\end{array}$ & $\begin{array}{l}\text { Dissatisfaction of } \\
\text { learner with regard to } \\
\text { specific learning } \\
\text { activities }\end{array}$ \\
\hline $\begin{array}{l}\text { Initially, at the start, it felt just like once you open module two, } \\
\text { it would be like it's going to read a story. After going through the } \\
\text { experience, you learn that these are serious things which we learn. } \\
\text { So, like, if you want to go to the qdex, you come and you go } \\
\text { and the teacher is there. You have a text book. The teacher has a text } \\
\text { book. So, you're ready. And, if they ask the question, they are there. } \\
\text { So, if you ask. If the teacher is not really good, you'll know. Because, } \\
\text { you have the book. }\end{array}$ & $\begin{array}{l}\text { Emotional } \\
\text { reassurance for the } \\
\text { learner regarding the } \\
\text { perceived value of } \\
\text { the course }\end{array}$ \\
\hline $\begin{array}{l}\text { The movement, that is the movement of the water from the } \\
\text { cilia, they went the water was coming, and we think that the first } \\
\text { pump, the second pump, and then eventually up to where it is needed. } \\
\text { For him it is a very good experience, you can pump water from deeper } \\
\text { place maybe faraway place up, and then on using powers. } \\
\text { So, this instruction here. You place upon one, so you can see } \\
\text { what screen is. You press like this. Then you saw a display. That's } \\
\text { what that instructions want you for the number one, then you go to the } \\
\text { number two. }\end{array}$ & $\begin{array}{l}\text { Perception of } \\
\text { learning from the } \\
\text { modules by } \\
\text { interacting with the } \\
\text { technology }\end{array}$ \\
\hline
\end{tabular}


\begin{tabular}{|l|l|}
\hline $\begin{array}{l}\text { For the video, add some background music. Maybe a game. } \\
\text { This part of it, I think it was very interesting, and certainly can, } \\
\text { next time we have to add more practical teaching }\end{array}$ & $\begin{array}{l}\text { Improvements learner } \\
\text { expects to see }\end{array}$ \\
what is the subject we are learning about. & \\
- Whant to go to qdex, because I want to read. I want to know & \\
catch up prints easily. It's not bad. So, you can to text to look at your \\
book. It explains so you can catch up. It's like you're reading it and \\
you know. So, it's not like, you're reading a story and after a day you \\
already forget it. So, you are reading it and you already know it. \\
- Like, I know camera one day. The first day they taught us how \\
to use these things, I just catch up. With these little guys help. The \\
first day, they taught us how to write our names. To register. To put \\
your identity. So, just understand everything that first day and then \\
know I can feel good.
\end{tabular}

Suggested changes to the course include stronger presence of hands-on activities that can be combined with small-scale developments in the community or the center. These can serve the dual purpose of demonstrating a basic engineering concept, for example, fixing a repaired radio. Additionally, the platform and tablet will be explored to identify ways in which to strengthen data collection, for example, by using the tablet as a tool to record the interaction of the students with the platform and thereby determine student behaviors and learning approaches. Assignments will be altered or standardized to facilitate more extensive data collection on student performance through exams, their learning through interviews, and observations, particularly in areas of key learning objectives. These data will be analyzed by the end of the course in December 2016.

The identification of potential collaborators from the engineering university was successful from the beta-test, exhibiting the potential for long-standing collaboration between all the stakeholders. This university is one of the most well-known engineering institutions in the country. The engineering dean and central administration is welcoming and supportive of this collaboration, clearly understanding the objectives of the project and the collaboration. The institute also has a well-established student association that functions as a leadership organization for the students. The students see this collaboration as an opportunity for mutual learning experiences that are often not gained during the course of formal university engineering training. Such a collaboration would be crucial to the long-term sustainability of the project by serving as an in-country partner with engineering capacity. The students identified from the engineering university are in the course of their engineering degree in different fields. These students will serve as mentors in two different aspects. First, the mentors will be a role model engineers conveying their interest and passion towards the field of engineering to the students at the center. Second, assisting in the design and construction of the solar powered pump would also serve as a hands-on community project for the university students. An important challenge in this collaboration is the sustainability of engaging the university students regularly with the students at the center. 
Teachers at the center were very welcoming of this course, as it proved to be more interactive and student-centered. Feedback from the teachers assisted in expanding the curriculum structure in terms of time and depth of the content. At the teachers' suggestion, the time in terms of number of weeks the course should cover was increased, considering the content and style of activities to be fairly new to the students. This would also allow them to learn at their own pace with sufficient and more flexible time. Another possible option is that this experimental course will have served as an incubator for instructional units that can be extracted and integrated into existing courses. For example, the model of experiential learning could be used in their formal science courses with the inclusion of hands-on activities and the support of technology (tablet) in hand as an interactive text book.

The development of the curriculum has thus far covered the overall design and structure. Course content is progressing in its development. An integral part of the curriculum and also the central piece of the backward design model "assessment" is still in progress.

\section{Challenges}

Developing content for the test module was challenging with the actual interaction being limited to virtual ways with the students and teachers, which resulted in frequent technological roadblocks more constrained interactions. One of the biggest challenges was filling the needs of each student and differentiating instruction to serve their diversified learning capabilities and prior experiences of the students. The beta-test helped in identifying how each student learns. From the initial set of interviews conducted, learning preferences are being noticed with respect to the format of the course content and the ease of interacting with the platform. The backward design model suggests that curriculum development proceed in the order of content, assessment, and pedagogy. In this work-in-progress, we began with the content, but for the purposes of betatesting the platform, we skipped assessment and moved ahead to pedagogy. Though pedagogy is still largely under construction, a structure has been framed by using the test modules developed. With the inclusion of various additional activities in the pedagogical structure, the assessment model is not yet clearly defined. One ongoing challenge is how best to weave assessment into the existing structure and how to continue the process of getting feedback from students on the assessment component of the curriculum.

\section{Next Steps}

The exposure of students to multiple tasks, multiple mentors and instructors, multiple opportunities and modes of learning, and multiple disciplines of engineering integrated together with technology is hypothesized to have significant impact on these students' engineering skills, knowledge, and attitudes. The course content development will progress along with identifying and developing a system for an appropriate assessment procedure. A key deliverable as part of this project will be an instructional package providing background and instructions for teachers to adopt this new structure and curriculum. This guide will introduce in greater detail the concepts covered in the engineering skills curriculum and will also provide insight into the scalability of the course. Future data collection will also provide the opportunity to assess the course's long-term viability and effectiveness as either a stand-alone course within the curriculum or as an incubator that can be integrated into existing courses. 


\section{References}

1. Streveler, R. A., Smith, K. A. \& Pilotte, M. Aligning course content, assessment, and delivery: Creating a context for outcome-based education. K. Mohd Yusof, S. Mohammad, N. Ahmad Azli, M. Noor Hassan, A. Kosnin S. K, Syed Yusof (Eds.), Outcome-Based Educ. Eng. Curric. Eval. Assess. Accreditation. Hershey, Pennsylvania IGI Glob. (2012).

2. Wiggins, G. P. \& McTighe, J. Understanding by design. (Ascd, 2005).

3. Dewey, J. Education and experience. (1938).

4. Kimani, S. \& Mercer, T. Tumaini. Retrieved May 2, 2016 at <http://tumainicenter.org/?page_id=19>

5. Goldstein, M., Graff-zivin, J. \& Nangami, M. HIV / AIDS , Antiretroviral Treatment, and Socio-economic Status : Preliminary Evidence from Western Kenya * Contents Acronyms, 1-21 (2005).

6. Kirkland, D. E. ' The Rose That Grew from Concrete': Postmodern Blackness and New English Education. English J. 69-75 (2008).

7. Masita-Mwangi, M., Mwakaba, N., Ronoh-Boreh, F. \& Impio, J. Building a case for m-learning in Africa: African youth perspectives on education. in CHI'12 Extended Abstracts on Human Factors in Computing Systems 521-536 (ACM, 2012).

8. Kimani, S. \& Mercer, T. Tumaini Children’s Transition Center. Retrived May 2, 2016 at $<$ http://tumainicenter.org/>

9. Li, K. C., Wong, T.-L., Cheung, S. K. S., Lam, J. \& Ng, K. K. Technology in Education. Transforming Educational Practices with Technology: International Conference, ICTE 2014, Hong Kong, China, July 2-4, 2014. Revised Selected Papers. 494, (Springer, 2015).

10. Muir-Herzig, R. G. Technology and its impact in the classroom. Comput. Educ. 42, 111-131 (2004).

11. Morley, F. P. A modern guide to effective K-12 curriculum planning. (Parker Pub. Co., 1973). at <https://books.google.com/books?id=CjAQAQAAMAAJ>

12. Colby, A. \& Sullivan, W. M. Formation of Professionalism and Purpose: Perspective from the Preparation for the Professions Program. U. St. Thomas LJ 5, 404 (2008).

13. Crawley, E. F., Malmqvist, J., Östlund, S., Brodeur, D. R. \& Edström, K. in Rethinking engineering education 11-45 (Springer, 2014).

14. Svinicki, M. D. Learning and motivation in the postsecondary classroom. (Anker Publishing Company, 2004).

15. Moore, D. M., Burton, J. K. \& Myers, R. J. Multiple-channel communication: The theoretical and research foundations of multimedia. Handb. Res. Educ. Commun. Technol. 851-875 (1996). 